\title{
How can clinicians counter viral misinformation?
}

\author{
Cite as: CMAJ 2021 May 3;193:E651-2. doi: 10.1503/cmaj.1095937
}

Posted on cmajnews.com on April 16, 2021

anadian public health experts are grappling with how to counter widespread misinformation about COVID-19 - much of which appears to be coming from the United States.

Canadians are not immune to America's infodemic, despite consistent domestic messaging emphasizing the seriousness of the pandemic, according to a recent study published in Frontiers in Political Science.

Researchers from McGill University analyzed data from the 200000 most active Twitter accounts in Canada, as well as survey data on media consumption. They found that most of the misinformation Canadians shared on Twitter came from American sources, and Canadians who consumed more American social media and news were more likely to believe and share misinformation and conspiracy theories that trivialized the pandemic.

The researchers did not analyze data from other social media platforms like Facebook and Instagram, and they identified misinformation by searching keywords like "plandemic" and "bioweapon," so they may have missed more subtle forms of misinformation. But given the "enormous sample sizes and similar dynamics observed across self-reported and actual behaviour," the authors concluded that American misinformation is a key driver of Canada's COVID-19 infodemic.

It's a concerning finding considering the saturation of Canadian Twitter feeds with American content. Nearly three in four Canadians followed more Americans than Canadians on Twitter, and nearly one in five followed more than 10 times as many Americans as Canadians.

According to the study authors, "social media platforms are likely playing a key role in deepening this exposure by saturating information streams with U.S.-based

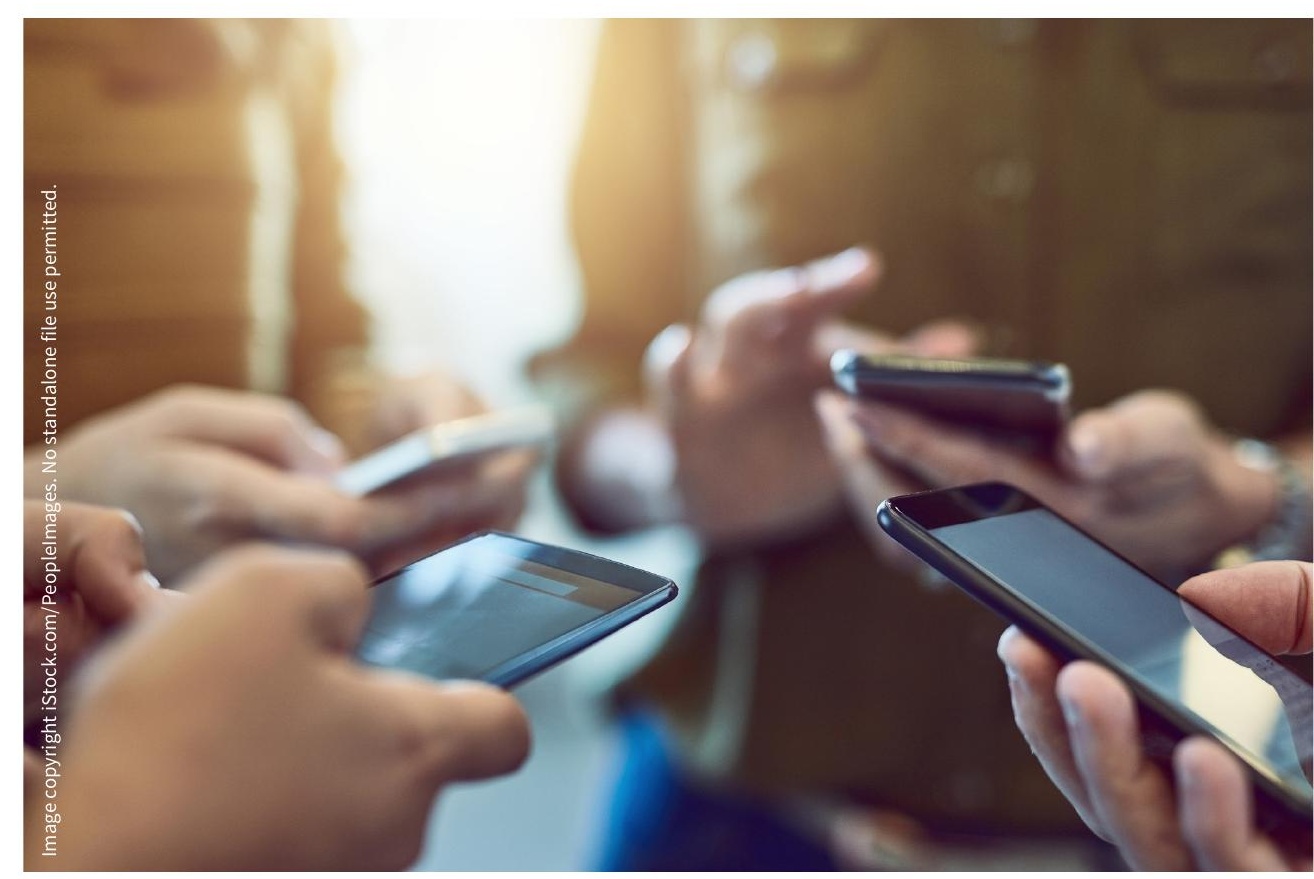

American misinformation is driving Canada's infodemic, according to McGill University researchers.

news." They also noted that lies tend to spread faster than the truth due to their novelty and emotional appeal.

"A lot of Canadians are struggling to understand COVID-19 denialism and anti-vaccination attitudes among their loved ones," stated lead author Aengus Bridgman, a Ph.D. candidate in political science at McGill. "It's hard for Canadian journalists, scientists and public health experts to be heard by the average Canadian, given all the noise generated by American sources."

Viral misinformation has long posed a threat to public health, but the pandemic put a spotlight on the problem, said experts at the Canadian Immunization Conference last winter.

According to Phillip Mai, co-director of Ryerson University's social media lab, people over 55 are most prone to fall for and share misinformation. And people who spread misinformation tend to look for discrepancies in public health messaging among jurisdictions.

"We need to make sure there's very little gap in what people in positions of authority are saying," said Mai. "Members of the public will pick and choose who they want to listen to."

Still, clinicians may be able to cut through the noise better than other authority figures - so long as they target their messages.

Julie Leask, a social scientist and professor at the University of Sydney, said clinicians must take time to understand patients' questions and concerns about the COVID-19 vaccines, and resist the impulse to interrupt and correct. People can hold a range of positions on vaccines and doctors should tailor their responses accordingly - encouraging patients who support vaccination, managing the 
expectations of those who are demanding the shots, and building trust with people who are hesitant.

Speaking at an Ontario Medical Association briefing earlier this year, Dr. Sarita Verma noted that racialized communities, particularly Black and Indigenous people, may not trust vaccines because of the health system's legacy of racism, exploitation and experimentation on people of colour. Other people may be hesitant because they or someone they know experienced adverse effects from previous vaccinations. Such concerns require culturally competent, patient-centred discussions, Verma said - there is no one-size-fitsall approach.

At the Canadian Immunization Conference, Leask recommended proactively addressing misinformation with patients and directing them to trusted sources, using phrases like "You may hear..." to open the conversation.

For those concerned about the safety of the vaccines, "we need to remind people that we've had very large trials that have been carefully done," Leask explained. However, it's also important to acknowledge risk and uncertainty - overconfidence undermines public trust.

\section{Putting risk in perspective}

Communication about the adverse events linked to AstraZeneca's COVID-19 vaccine has been particularly challenging. While there is enough evidence to say the AstraZeneca vaccine may cause very rare blood clots, according to Health Canada it is still very safe and effective and will remain on the market.
As of April 14, Canada has reported one case of immune thrombotic thrombocytopenia among 480000 people who have received the AstraZeneca vaccine. Other countries have reported anywhere from one case for every 40000 doses in Denmark to one in 250000 in the United Kingdom. Regulators are urging people to seek medical care if they experience severe headaches, shortness of breath, chest and stomach pain, leg swelling, or pinprick bruising following vaccination. Denmark has pulled the vaccine.

However, public health experts have stressed that the risk of death and blood clots from COVID-19 is much higher. One in five patients hospitalized with COVID19 develops some form of clot, and preprint research from Oxford University suggests the risk of rare blood clots in the brain is far higher in those with COVID-19 than in those who receive the AstraZeneca vaccine.

In a recent Globe and Mail article, André Picard argued that the backlash to the AstraZeneca vaccine reflects a collective failure to "put risk in perspective."

"As many scientists have observed, you have a greater risk of being badly injured in a car crash while driving to your vaccination appointment than actually being harmed by a COVID-19 vaccine," he wrote. "Drugs we take every day - Tylenol, birth-control pills, heart medications, sleeping pills - all have potentially severe side effects. We generally accept those risks, or at least don't think of them. Why do we expect vaccines to be magically problem-free when we don't expect that of other drugs?"
According to Dr. Noni MacDonald, a professor of pediatrics and infectious disease at Dalhousie University, how doctors frame information about risk can ease or escalate patients' anxiety. At the Canadian Immunization Conference, she gave the example of saying a vaccine is $99.99 \%$ safe versus saying it has a $0.1 \%$ chance of serious side effects.

MacDonald also urged clinicians to consider how much information they share at a time. While some people will be looking for a "full meal" of research, others will only need a "bite" to satisfy their questions. It's important not to overwhelm people with detail unless they ask for it, she said.

In addition to preparing patients to recognize misinformation, Macdonald said health workers should also prepare to address coincidental illnesses and deaths that arise after vaccination. Given how many millions of people are receiving COVID-19 vaccines, "Guillain-Barré will happen, sudden infant [death syndrome] will happen, spontaneous abortions will happen," without having anything to do with the shots, she said. "We need to make sure people don't jump to conclusions."

\section{Diana Duong, CMAJ}

Content licence: This is an Open Access article distributed in accordance with the terms of the Creative Commons Attribution (CC BY-NC-ND 4.0) licence, which permits use, distribution and reproduction in any medium, provided that the original publication is properly cited, the use is noncommercial (i.e., research or educational use), and no modifications or adaptations are made. See: https://creativecommons.org/ licenses/by-nc-nd/4.0/ 